\title{
A Global Comparison of Initial Pharmacy Education Curricula: An Exploratory Study
}

Naoko Arakawa, BPharm, MSc, PhD; Andreia Bruno-Tomé, BPharm Sci, PhD²; lan Bates, $\mathrm{MSc}^{3}$

${ }^{1}$ School of Pharmacy, University of Nottingham, UK; ${ }^{2}$ Faculty of Pharmacy and Pharmaceutical Sciences, Monash University, Australia

${ }^{3}$ University College London, School of Pharmacy, UK

\begin{abstract}
Background: Time-tabled curricular contents and syllabi reflect the actual delivery of the academic programme and one of key quality components in healthcare professional education. There is a need of global evidence base of Initial Pharmacy Education and Training (IPET) curricula for assisting the advancement of IPET globally.
\end{abstract}

Objectives: To seek the differences and similarities among IPET curricula and to explore relative trends and weighting of IPET curricula globally.

Methods: Sample curricular documents were collected purposively either through a parallel survey study investigating the structures and processes of IPET globally in collaboration with the International Pharmaceutical Federation Education (FIPEd), or through research team network. Collected textual documents containing IPET curricular contents were analysed by a mixed approach of the comparative content and framework analyses, using curriculum clusters in a guideline from the PHARMINE project.

Results: IPET curricular documents were collected from 16 countries and territories. The study showed study years spent in the IPET years range from four to six years, and a sample mean of average syllabus time spent per year is 728 hours/year (excluding outlier). There was a biggest variance in the pharmacy practice cluster (PRAC) among samples, ranging from 49.3 to $12.8 \%$, showing a significant negative correlation with the chemical science cluster (CHEM) $\gamma=-0.77(p<.0001)$. Categorised further into three curricular content groups, the study identified that there was variances in a tendency of the curricular orientation of science or practice-focus between countries.

Conclusion: The study allowed a first global comparison of IPET curricula from all WHO regions, which provided a better understanding of current IPET practice and delivery across nations and established evidence base to address challenges and gaps for further improvement of IPET curriculum in any country.

Keywords: Content analysis, Curriculum, Global comparison, Pharmacy Education, Initial Education and Training

\section{Introduction}

In any country or territory, improving health and pharmaceutical care for patients and populations requires the right number of pharmacy workforce $^{1}$ with the right competencies in the right places. Initial pharmacy education and training (IPET) is a pre-service professional higher education programme that leads a graduate to a formal registration as a pharmacist with a statutory board of each country where the education is offered. IPET plays an important role in providing trainees with entry level competencies and preparing them to reach their full potential as they develop further competencies to meet ever-changing health needs of

Corresponding author: Naoko Arakawa, BPharm, MSc, PhD School of Pharmacy, University of Nottingham, UK Email: Naoko.Arakawa@nottingham.ac.uk populations (High-Level Commission on Health Employment and Economic Growth, 2016; Langins \& Borgermans, 2015).

However, pharmacotherapy is becoming increasingly complex as new technologies emerge, and initial education and training programmes for health professionals, including pharmacy, are globally struggling to keep pace with these changes in health care (Anderson et al., 2010; Frenk et al., 2010).

Frenk et al. (2010) point out that healthcare professional curricula are often 'fragmented, outdated, and static,' which causes a mismatch between competencies of the professionals and health needs of the population. For example, Mutabaruka and his colleagues (2005) identified a discrepancy between the

\footnotetext{
${ }^{1}$ Pharmacy workforce refers to the whole of the pharmacy related workforce including registered pharmacist practitioners, pharmaceutical scientists, pharmacy technicians and other pharmacy support workforce cadres, preservice students/trainees) working in various settings related to pharmacy (International Pharmaceutical Federation, 2018).
} 
curricula and a specific health need for immunisations in the African region, as over $50 \%$ of all sampled in-service healthcare training institutions had no or inadequate immunisation training programme, despite the limited national immunisation coverage rates.

Research published in relevant journals (e.g. Innovations in Pharmacy, Pharmacy Education, American Journal of Pharmaceutical Education, Currents in Pharmaceutical Teaching and Learning) showcases innovations and advancements in focused areas of IPET, but there is limited evidence describing a holistic view of current IPET curricula globally. A comprehensive overview of IPET and its contexts of educational programmes across countries may help prevent partial or invalid implementation of learning from existing evidence.

Various platforms facilitate the sharing of innovations and advancements in IPET. For example, the International Pharmaceutical Federation Education (FIPEd) advocates for consistent use of a 'needs-based education' model to achieve the Pharmaceutical Workforce Development Goals (PWDGs) and provides reports and platforms to share different approaches globally for IPET advancement (International Pharmaceutical Federation, 2017a, 2017b). The 2013 FIPEd Global Education Report (International Pharmaceutical Federation Education Initiative, 2013) suggests variances in both capacity and infrastructure correlating with country economic indicators. However, there is no global comparison illustrating the baseline of the teaching components in IPET. This evidence gap prevents readers and pharmacy educators from evaluating their IPET compared with other countries, leaves them without empirical bases to drive reform.

According to Fish and Coles (2005), a curriculum is 'a blue print for educational practice' (p.24) which facilitates communication about the key principles and features of the programme. The design and organization of the curriculum contents/syllabus provide an understanding of the context for the profession within a given country. Time-tabled curriculum contents and syllabi are considered as 'curriculum in action' expressing the actual delivery of professional education (Coles \& Grant, 1985), which is particularly relevant to the quality of healthcare professional education (Frenk et al., 2010).

There is no literature available regarding the current curricular orientation and tendency of IPET in a global context, focusing on the curriculum in action. In a regional context, the PHARMacy education IN Europe (PHARMINE) project compared IPET curricula between 26 European countries aiming to ensure harmonisation of education throughout European countries in line with the mutual recognition of pharmacy programmes (Atkinson, 2014). The PHARMINE study revealed the variability in pharmacy programmes among the sample countries and noted a shift in curricular orientation from chemical sciences to medicinal sciences, emphasising a greater recognition of a clinical role for pharmacists (Atkinson, 2014). Nunes-da-Cunha et al. (2016) compared the pharmacy education curricula in European countries with the United States (US), focusing on the level of patient-centred care and showing variances between the curricular contents.

Exploring the variances and trends in IPET curricular contents globally provides a better understanding of current IPET practice across nations and helps establish an evidence base for identifying opportunities to enhance the quality of IPET curriculum across nations. The WHO (2016) developed a global strategy on human resources for health, raising the importance of strengthening the data (scope and completeness) on health workforce for assisting and implementing national, regional, and global strategy. Evidence on IPET curricula is important to consider for global support of pharmacy workforce development.

Therefore, this study aimed to seek the similarities and differences among IPET curricula in a global context by comparing the curricular contents of syllabus instructions and exploring relative trends and weighting of IPET curricula across nations. The global comparison of curricular contents will enhance understanding of educational and professional contexts in different countries and add to the evidence base for the improvement of pharmacy workforce development globally.

\section{Methods}

This exploratory study employed mixed methods of comparative content analysis and framework analysis of existing and available text-based documents describing curricular contents of IPET. Curriculum mapping using a content analysis of the course is helpful to delineate what is actually taught in the programme in order to make the curriculum more transparent to all its stakeholders (Harden, 2001; Plaza et al., 2007).

\section{Sample}

Samples for this study included documents or websites containing time-tabled curricular contents or syllabi. Timetabled curricular contents are lists of educational contents, sessions, or subjects set weekly with time allocated. This enables the calculation of contact hours in the documents and indicates only academic modular units. Porter (2002) identified a content analysis of instructional materials like text books is useful as one method of curriculum mapping, considering his experiences in primary and secondary education. However, Plaza et al. (2007) suggested the use of course syllabi for curriculum mapping in healthcare disciplines, as the courses do not use textbooks as heavily as primary and secondary education.

Sampling was conducted in two separate time-related phases. The first sampling phase was combined with a parallel study conducted during 2013 in collaboration with the International 
Pharmaceutical Federation Education (FIPEd), investigating the structures and processes of IPET globally (International Pharmaceutical Federation Education Initiative, 2013). Authors approached FIP member organisations, country and territory level contacts in education, and individual universities or associations and requested data regarding country-level IPET. The development of the questionnaire for the FIPEd parallel study can be found in a separate report (International Pharmaceutical Federation Education Initiative, 2013). The questionnaire called for country-level data relating to pharmacy and pharmaceutical education, workforce and relevant regulations, and was available in English, French, Portuguese, Arabic, Japanese, Chinese and Spanish. One question of the questionnaire was allocated to request respondents to send their country-level nationally agreed core curriculum or syllabus, or a URL link to this documentation. Countries responding with documents covering time-tabled or unitised curricular contents were included in the study.

An additional collection of relevant documents, phase 2, was conducted during 2013 within the FIPEd network to request data from the countries in the WHO regions that were not collected previously. This additional sampling enabled the examination of variances between all six WHO regions (Africa, Americas, South-East Asia, Europe, Eastern Mediterranean, and Western Pacific) and provided a clearer global pattern of IPET curricula. In this second sampling phase, documents were collected from individual universities of the country, which obtained country-specific accreditation. It was assumed that the curricular information from an individual university was aligned with the standards of IPET for the sampled country.

Syllabus subject labels together with academic credits or contact hours were retrieved from the collected documents. If documents were originally written in a non-English language (i.e. documents from Uruguay, Austria, Bosnia \& Herzegovina, Hungary and Japan), they were translated into English by one of the investigators (NA) using online Google Translate (California, USA). The collected data was aggregated and cleaned in Microsoft Office Excel 2010 (Washington, USA). Any unclear coding was clarified with a second investigator (IB) to ensure validity of coding. The cleaned data was analysed using Microsoft Office Excel 2010 (Washington, USA) and SPSS v22 (New York, USA).

\section{Analysis}

A mixed approach of content and framework analyses was applied to map and explore collected data. The categorisation framework applied for the study in the process of coding the data was a guideline from the PHARMINE project (Atkinson, 2014), which aimed to characterise European IPET curricula. The PHARMINE guideline consists of seven curriculum clusters: 1) Chemical Science, Pharmaceutical Chemistry and Biochemistry (CHEM), 2) Pharmaceutics, Technology, and Formulation (PHAR),(3) Maths and Physics (MATH), 4) Biological Sciences (BIO), 5) Pharmacology and Medicinal Science (MED),
6) Pharmacy Practice, Pharmaceutical Care, Clinical Pharmacy, Law and Social Pharmacy (PRAC), and 7) Generic (GEN). The study presented here also organized the seven curriculum clusters further into three groups (Chemistry group: clusters 1 , 2, 3); Physical Science group: clusters 4 and 5); and Practice group: clusters 6 and 7). This allowed evaluation of the general (and overtly broad) associations between basic science and applied pharmacy practice in this sample. A list of curriculum clusters and mapped curricular subject headings is summarised in Appendix 1.

To develop a metric for the categorised curricular subject (or topic) data, time-tabled teaching contact hours were used for this study, extracted from the obtained curricular documentation. In these documents, where time-tabled teaching contact hours were not used to quantify subjects or courses of the curricula, such as academic credits, these were converted into time-tabled teaching contact hours using the appropriate national or institutional guidelines (European Communities, 2009; International Student Exchange Programs, 2013; Ministry of Education Culture Sports Science and Technology Japan, 2010; Quality Assurance Agency for Higher Education, 2008; Thompson, 2005; Ulicna et al., 2011; Universidad de Deusto, 2013; US Department of Education, 2008). The academic credit conversions were carried out based on the curricula credit hours and availability of the conversion information in the sampled documents. The contact hour conversions used for this project are summarised in Appendix 2. Time-tabled teaching contact hours and teaching hours converted from academic credits are referred to as syllabus time in this document to compare curricular trends and orientations in a standardised way.

Comparisons were conducted using descriptive analysis, measuring the minimum, maximum, mean values and correlational statistics, together with graphical comparisons.

\section{Results \\ Demographic Data}

Sixteen countries provided existing documents of curricula or syllabus data, including the information of curricular subjects and their units (i.e., academic credits or contact hours). .

shows the sample representation of the country and the sample distribution in the WHO regions. Of the 16 collected documents, IPET curricula from India and Pakistan are nationally agreed core IPET curricula, and the others are for nationally accredited IPET programmes from schools of pharmacy in the sampled countries.

Of the 16 sample documents collected, four samples provide contact hours allocated for each subject (India, Malawi, Namibia, and Pakistan). Curricular subjects from the other 12 countries and territories were quantified using the academic credits available in the documents. As the US IPET is a Doctor of Pharmacy (PharmD) programme, which commonly requires science qualification or components prior to the programme, 
the prerequisite science components with academic credits informed by the sampled document were added to the PharmD syllabus data in order to consider the full components to become a pharmacist in the US. For the curricula data of Great Britain, the separate pre-registration training period required to become a licensed pharmacist was also added in order to globally analyse content and time allocations over the IPET programmes across nations.

The data were not normally distributed; non-parametric statistical tests (Spearman's correlation coefficient (Spearman, 1910)) were used in correlation analysis.

\section{Global Overview}

The undergraduate study years in a programme leading to registration as a licensed pharmacist range from four to six years at the time of this study (Table 1 ). The sample mean of the total syllabus time spent in each IPET programme is 3,639 hours (excluding outlier Japan) ranging from 2,130 to 12,525 hours (Figure 1).

\section{Curriculum Trends}

The weightings of each of seven curriculum clusters (CHEM, PHAR, MATH, BIO, MED, PRAC, and GEN) within the sampled IPET programmes also vary (Table 2 ). The study identified the biggest variance in the Pharmacy Practice cluster (PRAC) among samples (ranging from $49.3 \%$ to $12.8 \%$ ), as opposed to

\section{Discussion}

This study allowed a comparison of IPET curricula in a global context, showing variances in contact hours spent leading to registration as a pharmacist in the sampled countries, the orientation of sampled curriculum contents, the weighting of curricular clusters between countries, and correlations between curriculum clusters. It is the first study of its kind to provide a global trend of IPET curricula that includes data from all six WHO regions.

The documents sampled were not restricted to one type: the sampling was carried out through either a survey distribution or purposive approach by the investigators. In fact, using diverse sources to collect the data was applied in prior studies in different settings, when it comes to comparisons between multiple countries to help illustrate the comprehensive state of higher education curricula (Jain et al., 2012; Phillips, 2008).

Unitising the subject by contact hours enabled the comparison and weighting of the curricular clusters of IPET curricula between multiple countries where the curricular structures and the values of academic credits differ. However, it is important to note that the time-tabled teaching contact hours converted from many different academic credits do not express exact contact hours that the sampled IPET programmes offer. The course contents were offered in various ways including lectures, workshops, group discussions, or lab practices. These different teaching and learning approaches offer varying direct the Maths and Physics cluster (MATH) (ranging from $12.2 \%$ to $0.0 \%)$. The study found a significant negative correlation between the PRAC and CHEM clusters: as the proportion of the PRAC syllabus time increases, the proportion of the CHEM syllabus time decreases (Spearman's $r=-0.77$ and $p<0.0001$ ). Furthermore, a significant positive correlation between the MED and PHAR clusters was found (Spearman's $r=0.66, p=$ 0.005).

Seven curriculum clusters are further categorised into three to examine the tendency between science and practice in the sample. The study identified the variances of curricular orientations between sampled programmes. Figure 3 shows the variances of the proportion of three groups in IPET programme (chemistry, physical science, and practice) by samples. This indicates that, of the 16 countries collected, six samples (Uruguay, Hungary, Bosnia and Herzegovina, Croatia, Austria, and Iceland) have the tendency of chemistry-focused curriculum, while another six (India, the USA, Great Britain, Japan, Namibia, and Malta) tend to have practice-focused curricula. Four (Czech Republic, Pakistan, Malawi, and China Taiwan) tend to include all aspects in similar proportions. Of these four, Malawi and China Taiwan focus more on physical science in their curricula compared to the other groups. There was no significant correlation of the curricular orientations with any WHO regions.

contact hours within the scheduled period of the programme contents. This difference affected the conversion process of the academic credits to contact hours for analysis in the study. The academic credits were converted by using the lecture/seminar contact hours where the class often occurs in classroom in the most didactic teaching approach, which often differ from workshops or practical visits where more students' engagements required in more active learning approach. However, this limitation is also a strength of the study. Teaching approaches vary according to educators' understanding of the teaching method, as well as their interpretation and implementation. By converting the academic credits to standardised contact hours within the governmental or institutional guidelines, the trends and patterns of IPET curricula were explored in an objective manner.

\section{Variations in Pharmacy Curricula}

The study found variation in the syllabus time scheduled in the IPET programmes between the sampled 16 countries. The differences in the average syllabus time scheduled per year (Figure 2) suggests variation in approaches to teaching and learning in the sampled curricula. Figure 2 illustrates that the US and European countries have less syllabus time scheduled per year compared with other sampled regional countries. This suggests that IPET curricula in the US and European countries may require more self-directed learning compared to the sampled regional countries where students' learning time is included in their timetables. 
The study also revealed variation in the proportion of the seven curriculum clusters in total syllabus time. In particular, the pharmacy practice cluster (PRAC) has the biggest variance in the proportion of the total syllabus time between the sampled countries. The variability among the pharmacy curricula is welcomed by Atkinson (2014) as the variability allows academic freedom to develop other teaching and learning approaches in the programme. This also aligns with the FIP 'needs-based education' model (International Pharmaceutical Federation, 2017a), which allows variability of education based on various health needs in different countries.

Kelly and colleagues (2008) suggested that the use of curriculum mapping can provide evidence for identifying gaps or overlaps in contents by visualising the curriculum. However, Porter (2002) and Harden (2001) suggested a full curriculum mapping requires assessing many different aspects of the curriculum. In addition, 'a hidden curriculum,' which influences learners at the level of organisational structure and culture, and is not often articulated in the formal curriculum documents (Lempp \& Seale, 2004; Wachtler \& Troein, 2001). Thus, the results from this study do not cover the whole picture of the IPET curricula globally, nor encourage the standardization of IPET curricula globally.

\section{Trends and Weighting in Pharmacy Curricula}

The study identified the negative correlation between the proportion of chemical science and pharmacy practice syllabus times, as well as the positive association between medicinal science and pharmaceutics syllabus times. This indicates that these clusters are closely linked in IPET curriculum development. The difference in the orientation of the pharmacy curricula, as practice, science-focused, or balanced expressed in Figure 3, may express the variance in, or emphasis on, the role of pharmacists in the studied countries as WHO (2006) indicates.

In addition to varying pharmacist roles, the variety of the curricular orientations between countries may indicate varying extent of development of IPET curricula. IPET has traditionally focused on medicinal products, emphasising chemistry, pharmaceutics, and the regulation of medicine procurement systems. Depending on the degree of transformation of the IPET curriculum in the sampled countries, this may result from a failure to develop the 'needs-based education' that FIP supports (International Pharmaceutical Federation Education Initiative, 2013). With demographic changes, medical and pharmaceutical breakthroughs, and evolving healthcare systems, the role of pharmacists has broadened and shifted towards a more clinical orientation (Anderson et al., 2011; Breland, 2007). The variance observed between European countries was consistent with the PHARMINE study (Atkinson, 2014) and the other US/European countries comparative study (Nunes-da-Cunha et al., 2016), although European countries follow the Bologna Declaration, which agreed on the harmonization of pharmacy education and allows the mobility of professionals across Europe without additional training nor the validation of their degree. IPET has been continuously challenged globally to be transformed to prepare graduates to meet diverse healthcare needs, enabling them to work well in healthcare teams. Thus, IPET has been reformed across nations, although the speed of transformation varies beyond and within the countries and territories.

Although this study revealed variance in the curriculum orientation, it is unclear if there are any tendencies with regional contexts due to the sample size, although the study shows no significant correlation between practice/science curricular orientation and the WHO regional categories. Further research is needed with a higher number and a larger variety of samples to see a clearer global tendency in focus between IPET degree programmes.

\section{Biases and Limitations}

Several limitations of this study come from the nature of the sampling. Findings from this study are not generalisable due to the variety of countries represented. Fifty percent of the sample are from European countries. Further, the data from USA, UK and Japan cannot represent the curriculum of the whole country, as they have a large number of pharmacy schools.

Contact hours and learning hours calculated for comparative content analysis are considered as only the relative weight of the subject and how much the programme offers to students. The units for academic credits used for the calculation converted to contact/learning hours may not be exactly the same as the actual contact hours spent for students. Teachers and academics often have extra contact hours with students outside of time-scheduled classes.

Furthermore, the data collected for this study does not cover the exact extent to which topics were reinforced in the curriculum (Litaker et al., 2004; Plaza et al., 2007). This may cause an underreporting of some curriculum clusters and groups in the results.

\section{Contributions by authors}

$1^{\text {st }}$ author: concept, method design, data collection, data analysis, first draft production and final approval of the manuscript.

$2^{\text {nd }}$ author: data collection, revising drafts and final approval of the manuscript.

$3^{\text {rd }}$ author: concept, method design, data analysis, revising drafts and final approval of the manuscript. 
Ethical consideration: This study utilised an unobtrusive approach using existing data and documents that are publicly available. Thus, the study did not require ethical approval. Acknowledgement: Authors thank for the support for the project given by the International Pharmaceutical Federation and respondents who provided curricular documents for the project.

Conflicts of Interest: None

Funding/support: Naoko Arakawa financial support for her doctoral programme during the project from the University College London

\section{References}

Anderson, C., Bates, I., \& Brock, T. (2011). Seven Billion Humans and 98 Trillion Medicines Doses. American Journal of Pharmaceutical Education, 75(10), Article 194. doi:10.5688/ajpe7510194

Anderson, C., Bates, I., Futter, B., Gal, D., Rouse, M., \& Whitmarsh, S. (2010). Global Perspectives of Pharmacy Education and Practice. World Medical \& Health Policy, 2(1), Article 2. doi:10.2202/19484682.1052

Atkinson, J. (2014). Heterogeneity of Pharmacy Education in Europe. Pharmacy, 2, 231-243. doi:10.3390/pharmacy2030231

Breland, B. D. (2007). Believing what we know: pharmacy provides value. American Journal of Health-System Pharmacy, 64(12), 1284-1291. doi:10.2146/ajhp070015

Coles, C. R., \& Grant, J. G. (1985). Curriculum evaluation in medical and health-care education. Medical Education, 19, 405-422. doi:10.1111/j.13652923.1985.tb01345.x

European Communities. (2009). ECTS Users' Guide. Brussels. Retrieved from:

http://ec.europa.eu/education/tools/docs/ectsguide en.pdf

Fish, D., \& Coles, C. (2005). Medical Education: Developing a curriculum for practice. Berkshire: Open University Press.

Frenk, J., Chen, L., Bhutta, Z. A., Cohen, J., Crisp, N., Evans, T., Fineberg, H., Garcia, P., Ke, Y., Kelley, P., Kistnasamy, B., Meleis, A., Naylor, D., Pablos-Mendez, A., Reddy, S., Scrimshaw, S., Sepulveda, J., Serwadda, D., \& Zurayk, H. (2010). Health professionals for a new century: transforming education to strengthen health systems in an interdependent world. The Lancet, 376(9756), 1923-1958. doi:10.1016/s01406736(10)61854-5

Harden, R. M. (2001). AMEE Guide No. 21: Curriculum mapping: a tool for transparent and authentic teaching and learning. Medical Teacher, 23(2), 123137. doi:10.1080/01421590120036547
High-Level Commission on Health Employment and Economic Growth. (2016). Working for health and growth: investing in the health workforce. Geneva. Retrieved from:

http://apps.who.int/iris/bitstream/10665/250047/1/ 9789241511308-eng.pdf?ua=1

International Pharmaceutical Federation. (2017a). Research, development and evaluation strategies for pharmaceutical education and the workforce: $A$ global report. The Hague. Retrieved from: https://www.fip.org/file/1385

International Pharmaceutical Federation. (2017b). Transforming Pharmacy and Pharmaceutical Sciences Education in the Context of Workforce Development. The Hague. Retrieved from: https://www.fip.org/file/1387

International Pharmaceutical Federation. (2018). Pharmacy Workforce Intelligence: Global Trends Report. The Hague. Retrieved from: https://www.fip.org/file/2077

International Pharmaceutical Federation Education Initiative. (2013). 2013 FIPEd Global Education Report. The Hague. Retrieved from: http://www.fip.org/files/fip/FIPEd Global Education Report 2013.pdf

International Student Exchange Programs. (2013). Transcript Evaluation Guidelines. Retrieved from https://www.isepstudyabroad.org/

Jain, G., Mazhar, M. N., Uga, A., Punwani, M., \& Broquet, K. E. (2012). Systems-Based Aspects in the Training of IMG or Previously Trained Residents: Comparison of Psychiatry Residency Training in the United States, Canada, the United Kingdom, India, and Nigeria. Academic Psychiatry, 36(4), 307-315. doi:0.1176/appi.ap.11030047

Kelley, K. A., McAuley, J. W., Wallace, L. J., \& Frank, S. G. (2008). Curricular mapping: process and product. American Journal of Pharmaceutical Education, 72(5), 100. doi:10.5688/aj7205100

Langins, M., \& Borgermans, L. (2015). Strengthening a competent health workforce for the provision of coordinated/integrated health services: working document. Copenhagen. Retrieved from: http://www.euro.who.int/ data/assets/pdf file/001 0/288253/HWF-Competencies-Paper-160915final.pdf

Lempp, H., \& Seale, C. (2004). The hidden curriculum in undergraduate medical education: qualitative study of medical students' perceptions of teaching. BMJ, 329, 770-773. doi:10.1136/bmj.329.7469.770

Litaker, D., Cebul, R. D., Masters, S., Nosek, T., Haynie, R., \& Smith, C. K. (2004). Disease prevention and health promotion in medical education: Reflections from an academic health center. Academic Medicine, 79(7), 690-697. doi:10.1097/00001888-200407000-00017 
Ministry of Education Culture Sports Science and Technology Japan. (2010). A study of ACTS and credit transfer system of ASEAN+3 nations. Tokyo. Retrieved from: http://www.mext.go.jp/component/b menu/houdou $\angle$ icsFiles/afieldfile/2011/10/07/1311779 4.pdf

Mutabaruka, E., Nshimirimana, D., Goilav, C., \& Meheus, A. (2005). EPI Training Needs Assessment in 12 African Countries, 2002-2004. Communicable Diseases Bulletin for the African Region, 3(2), 1-4. Retrieved from https://repository.uantwerpen.be/desktop/irua.

Nunes-da-Cunha, I., Arguello, B., Martinez, F. M., \& FernandezLlimos, F. (2016). A Comparison of Patient-Centered Care in Pharmacy Curricula in the United States and Europe. American Journal of Pharmaceutical Education, 80(5), 83. doi:10.5688/ajpe80583

Phillips, S. P. (2008). Models of medical education in Australia, Europe and North America. Medical Teacher, 30(7), 705-709. doi:10.1080/01421590802061134

Plaza, C. M., Draugalis, J. R., Slak, M. K., Skrepnek, G. H., \& Sauer, K. A. (2007). Curriculum Mapping in Program Assessment and Evaluation. American Journal of Pharmaceutical Education, 71(2), 20. doi:10.5688/aj710220

Porter, A. C. (2002). Measuring the content of instruction: Uses in research and practice. Educational Researcher, 31(7), 3-14. doi:10.3102/0013189x031007003

Quality Assurance Agency for Higher Education. (2008). Higher education credit framework for England: guidance on academic credit arrangements in higher education in England. Mansfield. Retrieved from: https://www.qaa.ac.uk/docs/qaa/qualitycode/academic-creditframework.pdf?sfvrsn=940bf781 12
Spearman, C. (1910). Correlation calculated from faulty data. British Journal of Psychology, 3(3), 271-295. doi:10.1111/j.2044-8295.1910.tb00206.x

Thompson, T. (2005). Admissions wRAO-UP Newsletter, February 2005: Recruitment, Admissions, and Preparation Knowledge Community. Washington, DC. Retrieved from: https://www.nafsa.org/

Ulicna, D., Allinson, R., Javorka, Z., Dunne, A., Bonneau, M., Fleury, S., Myers, J., \& Yang, S.-W. (2011). Order 144 Study on the use of credit systems in higher education cooperation between the EU and hte US - Final Report. Brussels. Retrieved from: https://www.technopolis-group.com/wpcontent/uploads/2014/05/1472-Order-144-finalreport-revised-Nov-11-no-TC-1.pdf

Universidad de Deusto. (2013). CLAR - Latin American Reference Credit (Vol. 2014). Bilbao: Universidad de Deusto.

US Department of Education. (2008). Structure of the U.S. Education System: Credit Systems. Washington, DC. Retrieved from:

https://www2.ed.gov/about/offices/list/ous/internati onal/usnei/us/credits.doc.

Wachtler, C., \& Troein, M. (2001). A hidden curriculum: mapping cultural competency in a medical programme. Medical Education, 37, 861-868. doi:10.1046/j.1365-2923.2003.01624.x

World Health Organization. (2006). Working together for health: the world health report 2006. Geneva. Retrieved from: http://www.who.int/whr/2006/whr06 en.pdf

World Health Organization. (2016). Global strategy on human resources for health: Workforce 2030. Geneva. Retrieved from: http://apps.who.int/iris/bitstream/10665/250368/1/ 9789241511131-eng.pdf?ua=1 
Table 1. The Number of Samples Collected and Years of Study in the IET Programme.

\begin{tabular}{|c|c|c|c|c|}
\hline WHO region & Country & Sample & $\begin{array}{c}\text { Total Number of } \\
\text { Pharmacy Schools }\end{array}$ & Years of Study \\
\hline \multirow[t]{2}{*}{ Africa } & Malawi & 1 & 1 & 4 \\
\hline & Namibia & 1 & 1 & 4 \\
\hline \multirow[t]{2}{*}{ Americas } & Uruguay & 1 & 1 & 5 \\
\hline & USA & 1 & 129 & 6 \\
\hline Eastern Mediterranean & Pakistan & $\begin{array}{c}\text { National } \\
\text { Curriculum }\end{array}$ & 41 & 6 \\
\hline \multirow[t]{8}{*}{ Europe } & Austria & 1 & 3 & 4.5 \\
\hline & Bosnia \& Herzegovina & 1 & 2 & 5 \\
\hline & Croatia & 1 & 1 & 5 \\
\hline & Czech Republic & 1 & 1 & 5 \\
\hline & Great Britain & 1 & 26 & 5 \\
\hline & Hungary & 1 & 4 & 5 \\
\hline & Iceland & 1 & 1 & 5 \\
\hline & Malta & 1 & 1 & 5 \\
\hline South East Asia & India & $\begin{array}{c}\text { National } \\
\text { Curriculum }\end{array}$ & 1026 & 6 \\
\hline \multirow[t]{2}{*}{ Western Pacific } & China Taiwan & 1 & 7 & 5 \\
\hline & Japan & 1 & 74 & 6 \\
\hline
\end{tabular}


Table 2. Proportion of Each Curriculum Cluster in Total Syllabus Time of Sampled Pharmacy Programme.

\begin{tabular}{|c|c|c|c|c|c|c|c|c|}
\hline & \multirow{2}{*}{$\begin{array}{c}\text { Total } \\
\text { timetabled } \\
\text { syllabus } \\
\text { time (Hours) }\end{array}$} & \multicolumn{7}{|c|}{$\begin{array}{l}\text { Proportion of Curriculum Cluster in Total Syllabus Time } \\
\text { in a Pharmacy Programme (\%) (Contact Hours spent in a programme (hours)) }\end{array}$} \\
\hline & & CHEM & MATH & MED & PHAR & BIO & PRAC & GEN \\
\hline \multicolumn{9}{|l|}{ Country } \\
\hline China Taiwan & 4014 & $19.3(774)$ & $2.7(108)$ & $19.7(792)$ & $7.2(288)$ & $17.9(720)$ & $28.3(1134)$ & 4.9 (198) \\
\hline Croatia & 2636.25 & $36.3(956.25)$ & $4.3(112.5)$ & 16.5 (435) & $8.0(210)$ & $11.7(307.5)$ & 18.5 (487.5) & $4.8(127.5)$ \\
\hline $\begin{array}{l}\text { Czech } \\
\text { Republic }\end{array}$ & 2827.5 & $25.7(727.5)$ & $0.8(22.5)$ & $18.3(517.5)$ & $11.1(315)$ & $5.3(150)$ & $22.8(645)$ & $15.9(450)$ \\
\hline Iceland & 2295 & $20.9(480)$ & $5.2(120)$ & $24.2(555)$ & $13.1(300)$ & $6.5(150)$ & $15.7(360)$ & $14.4(330)$ \\
\hline Malawi & 2864 & $10.0(287)$ & $1.6(45)$ & $34.3(981)$ & $18.2(522)$ & $4.0(114)$ & $23.4(671)$ & $8.5(244)$ \\
\hline Namibia & 5568 & $13.2(736)$ & $1.1(64)$ & $21.6(1200)$ & $9.2(512)$ & $5.5(304)$ & $42.8(2384)$ & $6.6(368)$ \\
\hline Malta & 3225 & $10.2(330)$ & $2.3(75)$ & $12.6(405)$ & $8.4(270)$ & $4.7(150)$ & 49.3 (1590) & $12.6(405)$ \\
\hline $\begin{array}{l}\text { Bosnia and } \\
\text { Herzegovina }\end{array}$ & 3750 & $28.4(1065)$ & $6.0(225)$ & $23.6(885)$ & $17.2(645)$ & $8.0(300)$ & $12.8(480)$ & $4.0(150)$ \\
\hline Uruguay & 5160 & $36.0(1860)$ & $12.2(630)$ & $12.5(645)$ & $10.2(525)$ & $8.1(420)$ & $20.6(1065)$ & $0.3(15)$ \\
\hline USA & 3025 & $14.7(445)$ & $6.9(210)$ & $8.1(245)$ & $5.3(160)$ & $9.3(280)$ & 35.5 (1075) & $20.2(610)$ \\
\hline Japan & 12525 & $17.0(2130)$ & $2.3(285)$ & $5.0(630)$ & $5.0(630)$ & $3.4(420)$ & 40.4 (5055) & 26.9 (3375) \\
\hline Austria & 2524.25 & $30.2(761.25)$ & $1.5(37.5)$ & $23.5(592.5)$ & $15.6(393.75)$ & $6.5(165)$ & 12.9 (326.75) & $9.8(247.5)$ \\
\hline Hungary & 2130 & 28.5 (607.5) & 4.9 (105) & $16.9(360)$ & $18.3(390)$ & $4.2(90)$ & $17.3(367.5)$ & $9.9(210)$ \\
\hline India & 7320 & $14.8(1080)$ & $2.2(160)$ & $19.7(1440)$ & $13.7(1000)$ & $5.5(400)$ & $35.0(2560)$ & $9.3(680)$ \\
\hline Pakistan & 4000 & $16.0(640)$ & $1.5(60)$ & $30.0(1200)$ & $16.0(640)$ & $3.5(140)$ & $24.5(980)$ & $8.5(340)$ \\
\hline Great Britain & 3246.367 & $11.0(365.24)$ & $0.0(0)$ & $16.7(542.26)$ & $14.4(468.78)$ & $5.2(168.91)$ & $45.1(1465.23)$ & 7.6 (244.95) \\
\hline Sample Mean & $\begin{array}{c}3639.0 \\
\text { (excluding } \\
\text { outlier } \\
\text { Japan) }\end{array}$ & 20.8 & 3.5 & 18.9 & 11.9 & 6.8 & 27.8 & 10.3 \\
\hline
\end{tabular}

* Note for abbreviation: CHEM - Chemical Science, Pharmaceutical Chemistry and Biochemistry; MATH - Maths and Physics; MED -

Pharmacology and Medicinal Science; PHAR - Pharmaceutics, Technology, and Formulation; BIO - Biological Sciences; PRAC - Pharmacy Practice,

Pharmaceutical Care, Clinical Pharmacy, Law and Social Pharmacy (PRAC); and GEN - Generic Appendices 
Figure 1. Total Timetabled Syllabus Time Offered in Pharmacy Programme (Hours)

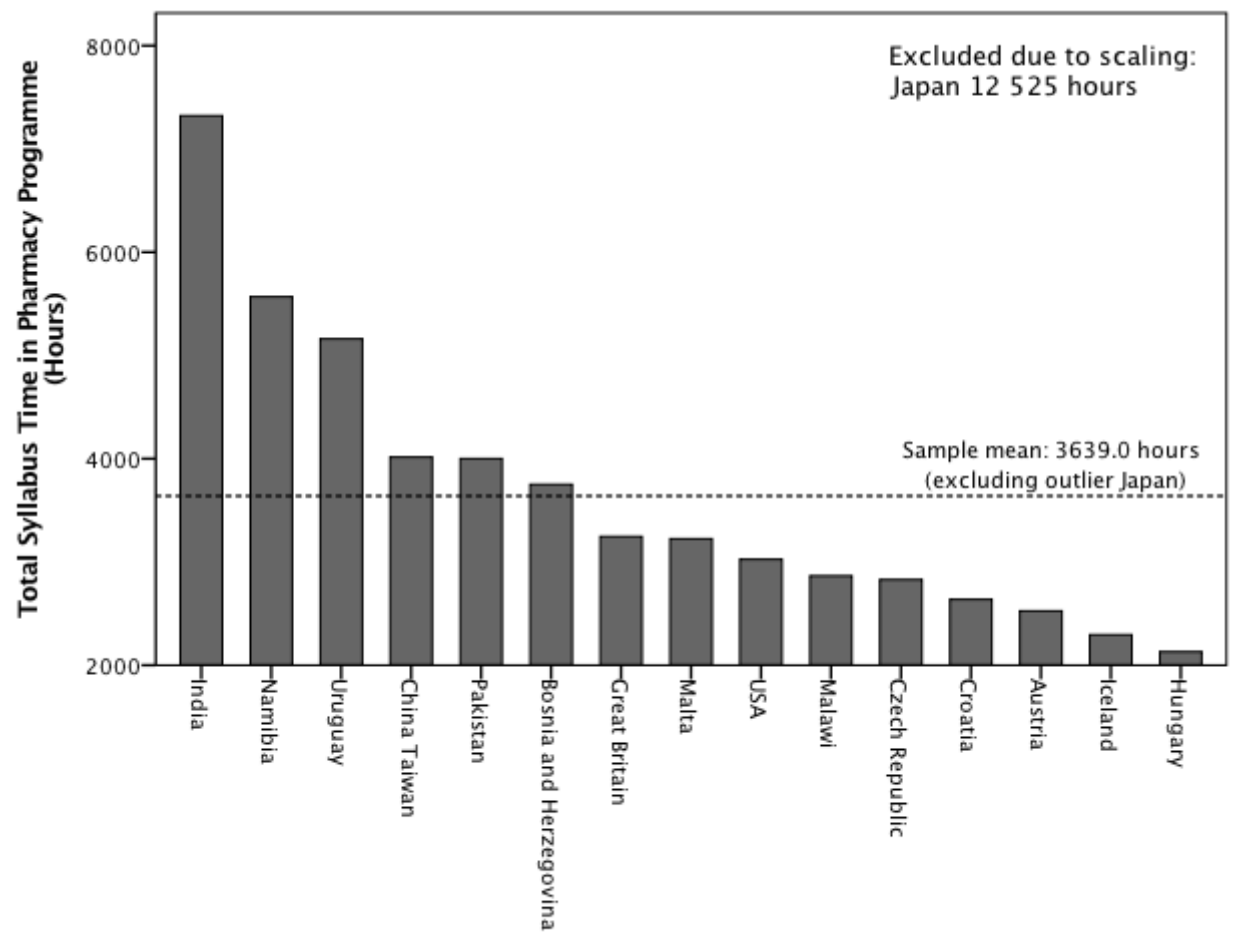

Average syllabus time spent in a year also varies among the sampled curricula. A sample mean of average syllabus time per year is 728 hours/year (excluding outlier Japan), ranging from 383 to 2,088 hours/year (Figure 2).

Figure 2. Average Timetabled Syllabus Time Offered in a Year of Pharmacy Programme (Hours)

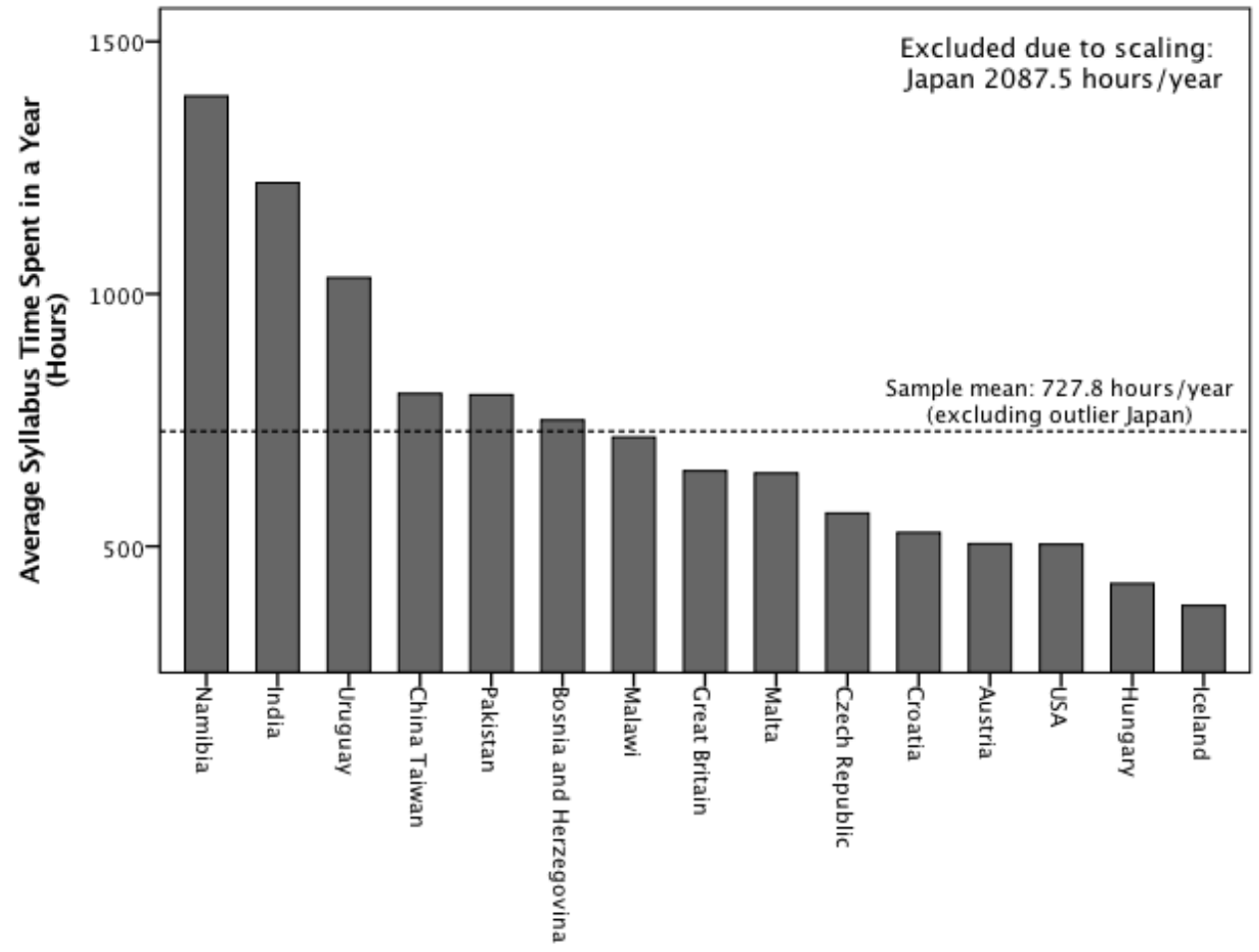


Figure 3. Proportion of Three Categories for the Contact Hours in Pharmacy Programme by Sampled Countries.

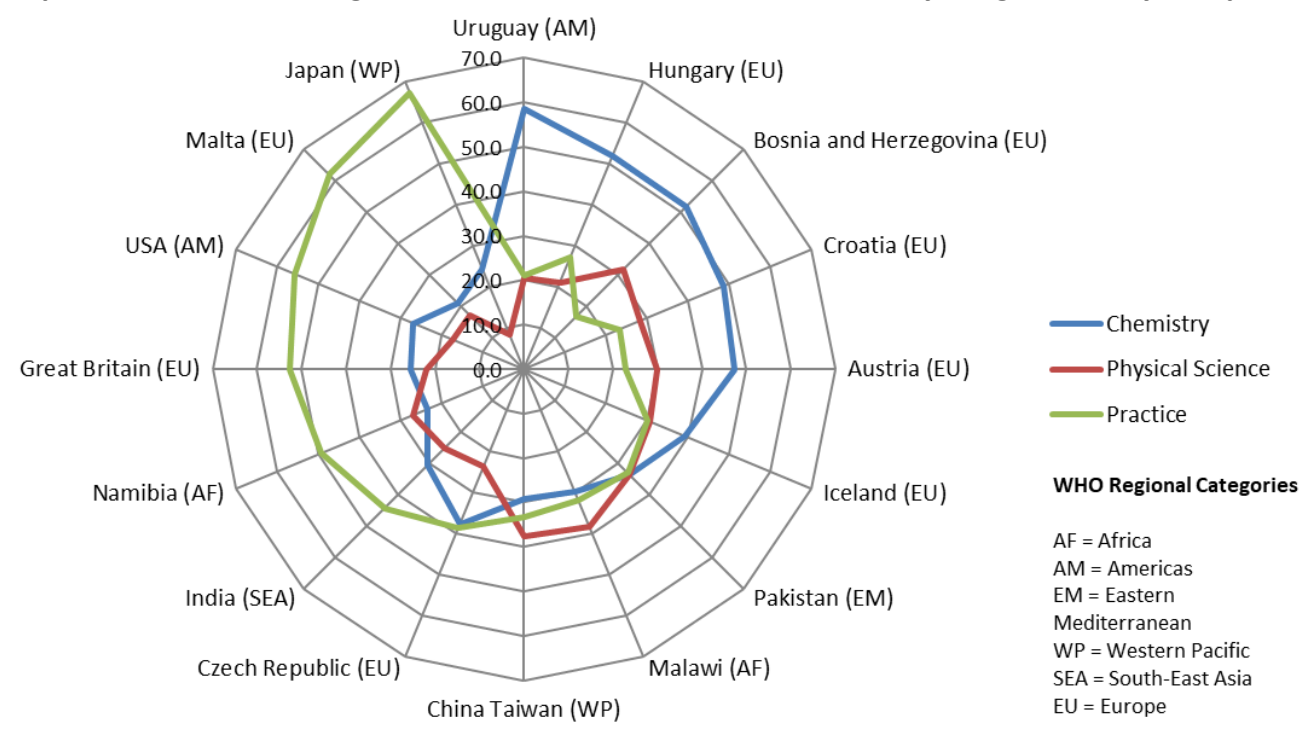


Appendix 1. A List of Curriculum Clusters and Curricular Subject Headings.

\begin{tabular}{|c|c|}
\hline Cluster & Syllabus Headings in the Cluster \\
\hline \multirow[t]{6}{*}{ CHEM } & Analytical Chemistry \\
\hline & Biochemistry \\
\hline & Chemistry (General, Organic and Inorganic, Including Radiochemistry and Spectrometry) \\
\hline & Chemical Laboratory / Instrumental Analysis \\
\hline & Pharmaceutical Chemistry / Pharmacopeial Analysis / Pharmaceutical Analysis \\
\hline & $\begin{array}{l}\text { Physicochemistry (Medicinal Physicochemistry / Physical Chemistry / Biophysics / Structure Activity Relationships } \\
\text { / Drug Design \& Discovery) }\end{array}$ \\
\hline \multirow[t]{2}{*}{ MATH } & Physics \\
\hline & Mathematics / Statistics \\
\hline \multirow[t]{6}{*}{ MED } & Dermatology, Human Physiology, Anatomy \\
\hline & Immunopharmacology / Immunology (including Haematology) \\
\hline & Pharmacognosy, Plant Physiology, Phytotherapy and Homeopathy, Botany \\
\hline & Pharmacology \\
\hline & Pathophysiology (including Citology and Histology) \\
\hline & Medicinal Chemistry \\
\hline \multirow[t]{7}{*}{ PHAR } & Pharmaceutical Technology \\
\hline & Veterinary Pharmacy \\
\hline & Pharmaceutics / Galenics Formulation \\
\hline & Pharmacokinetics and Biopharmacy (Drug disposition and metabolism / Drug Delivery) \\
\hline & Quality Assurance in Pharmaceutical industry (Quality Assurance in Production) \\
\hline & Toxicology and Environmental Chemistry \\
\hline & Cosmetology \\
\hline \multirow[t]{8}{*}{$\mathrm{BIO}$} & Biology (General and Cellar) / Microbiology \\
\hline & Anti-infective Therapy (Bacteriology / Virology / Parasitology / Microbial Pathology / Chematotherapy) \\
\hline & Biological Analysis and Lab Diagnosis \\
\hline & Biostatistics \\
\hline & Biotechnology \\
\hline & Genetics \\
\hline & Molecular Biology (Molecular aspects of the action of drugs and their targets) \\
\hline & Nutrition and Bromatology (including Food Hygiene and Technology) \\
\hline \multirow[t]{10}{*}{ PRAC } & Clinical Pharmacy (Pharmacotherapy / Pharmaceutical Care) \\
\hline & Dispensing Process, drug prescription, prescription analysis (detection of adverse effects and drug interactions) \\
\hline & Ethics (Professional Ethics / Deontology) \\
\hline & Legislation (Pharmacy Law) \\
\hline & Management and Pharmaceutical Planning \\
\hline & Management, Legislation and Economics applied to the Pharmaceutical Industry \\
\hline & Pharmacy Practice / Clinical Training \\
\hline & Medicine Information \\
\hline & Industrial Pharmacy \\
\hline & Public Health / Sociology / Epidemiology \\
\hline \multirow[t]{8}{*}{ GEN } & Communication and Transferrable Skills \\
\hline & Psychology \\
\hline & Leadership \\
\hline & Computer Science / Computer Skills \\
\hline & History of Pharmacy \\
\hline & Languages \\
\hline & Physical Training / Sports \\
\hline & Research Methods / Projects \\
\hline
\end{tabular}


Appendix 2. Contact Hour Conversions per Different Academic Credits by Sampled Countries.

\begin{tabular}{|c|c|c|c|c|c|c|}
\hline & \multicolumn{6}{|c|}{ Contact Hours per Credit (Hours) } \\
\hline & 15 & 30 & 45 & 60 & 75 & 90 \\
\hline US semester credit & 1 & 2 & 3 & 4 & 5 & 6 \\
\hline US quarter credit & 1.5 & 3 & 4.5 & 6 & 7.5 & 9 \\
\hline China Taiwan & 0.83 & 1.67 & 2.5 & 3.33 & 4.17 & 5 \\
\hline Japan & 0.5 & 1 & 1.5 & 2 & 2.5 & 3 \\
\hline ECTS* & 2 & 4 & 6 & 8 & 10 & 12 \\
\hline Great Britain & 4 & 8 & 12 & 16 & 20 & 24 \\
\hline Uruguay & 1 & 2 & 3 & 4 & 5 & 6 \\
\hline
\end{tabular}

*Note: ECTS is the European Credit Transfer and Accumulation System. 